Tohoku J. Exp. Med., 2004, 204, 215-219

\title{
Clinical and Ultrasonographical Findings in Patients with Multiseptate Gallbladder
}

\author{
Besir Erdogmus, Burhan Yazici, Betul Ayca Ozdere and Yusuf Akcan ${ }^{1}$ \\ Department of Radiology, and ${ }^{1}$ Gastroenterology, Abant Izzet Baysal University, \\ Duzce Medical School, Duzce, Turkey
}

Erdogmus, B., Yazici, B., Ozdere, B.A. and Akcan, Y. Clinical and Ultrasonographical Findings in Patients with Multiseptate Gallbladder. Tohoku J. Exp. Med., 2004, 204 (3), 215-219 - Multiseptate gallbladder is one of the rare congenital malformations of the gallbladder. We present clinical and ultrasonographic findings in seven patients with multiseptate gallbladder. One of them had nausea and right upper quadrant pain, three had recurrent abdominal pain, while the remaining three patients had no symptoms, physical finding and laboratory abnormality which could be attributable to the biliary system. In patients with multiseptate gallbladder, disturbed motility of the gallbladder may be an etiopathogenetic factor for stasis of bile flow and in turn for development of cholelithiasis, cholecystitis and right upper quadrant pain. - calculous cholecystitis; multiseptate gallbladder; ultrasound (C) 2004 Tohoku University Medical Press

Multiseptate gallbladder (MSG) is the rare abnormality among the congenital abnormalities of the gallbladder. In this abnormality, gallbladder is divided into compartments at different sizes by thin septa (Ozgen et al. 1999; Miwa et al. 2000). Although there are many reviews in the literature about MSG, ultrasonographic findings of MSG have not been reported. In this study, we aimed to present both clinical and ultrasonographic findings of patients with MSG.

\section{Material and Methods}

Seven cases were included in this study (Table 1). Their mean age was twenty-nine (range 10-45 years). Four of them were female, and three were male. All cases were examined by ultrasonography (Toshiba SSA 270A, Toshiba, Tokyo). Diagnosis was made incidentally in three asymptomatic patients during ultrasonography performed for renal examination. Remainders had symptoms attributable to biliary system pathologies. Characteristics of patients were presented in Table 1.

\section{RESUlts}

Clinical characteristics and results of ultrasonography examination of all cases were summarized in Table 2. Case one was a ten year old female patient suffering from nausea and right upper quadrant pain. But she did not have any

Received June 2, 2004; revision accepted for publication September 14, 2004.

Address for reprints: Besir Erdogmus, A.İ.B.Ü Düzce Tıp Fak. Radyoloji AD, Konuralp street, 81620 Düzce, Turkey.

e-mail: besirerdo@hotmail.com 
TABLE 1. Age and gender of patients.

\begin{tabular}{ccc}
\hline Case & Age & Gender \\
\hline 1 & 10 & Female \\
2 & 23 & Male \\
3 & 33 & Female \\
4 & 40 & Female \\
5 & 12 & Male \\
6 & 45 & Male \\
7 & 40 & Female \\
\hline
\end{tabular}

complaint of icterus, pruritis or acholic stool and any family history of cholelithiasis. In her physical examination, she had right upper quadrant tenderness. Her blood smear revealed leukocytosis. Ultrasonographic examination showed an oedematous multiseptate gallbladder with a thick wall. It possessed some sludge and multiple-milimetric stones with posterior acoustic shadowing. We diagnosed an association of MSG and calculous cholecystitis in this patient with clinical and ultrasonography findings (Figs. 1A and 1B). The diagnosis was also confirmed histopathologically after the operation.

Cases 2, 3 and 4 were being followed up because of nephrolithiasis. None of these patients had biliary symptoms (Table 2). MSG was detected incidentally during ultrasonographic examination. Case 4 had additionally Phrygian cap deformity with folding of the gallbladder fundus over its corpus (Fig. 2). Since these patients had no clinical symptoms, no medical or surgical treatment were advised. No change was detected in clinical and ultrasonographic findings of these patients one year later.

Case 5 came to our hospital with recurrent abdominal pain while case 6 and 7 with recurrent epigastric pain. These three patients had no any other remarkable finding in their clinical examination and laboratory tests to explain their nonspecific pain. Multiple septa localized especially in the corpus and neck of the gallbladder were the only finding detected in their ultrasonographic examination (Figs. 3 and 4).

\section{Discussion}

The multiseptate gallbladder is thought as a congenital malformation (Adear and Barki 1990). Histologically, absence of muscle fibers within the septa supports the probability of a congenital developmental abnormality and the early maturation of the gallbladder lumen as the cause of MSG (Esper et al. 1992). The gallbladder is divided into multiple compartments by thin septa and presents a honeycomb appearance in MSG. Septa affect the gallbladder lumen diffusely in most of the patients with MSG, but the gallbladder lumen can be rarely partially affected (Ozgen et al. 1992). In our study, only the neck of the gallbladder was involved in two of the seven cases, and the septa were seen in the neck and the corpus of the gallbladder in the rest of the patients.

Phrygian cap deformity is characterized by the folding of the fundus of the gallbladder over its corpus. Incidence of the abnormality is approximately 4\% (Laing 1987). Only one case of MSG and Phrygian cap deformity with acute cholecystitis has been reported in the literature (Esper

TABLE 2. Clinical characteristics and findings of ultrasonography.

\begin{tabular}{clll}
\hline Case & \multicolumn{1}{c}{ Symptoms } & Physical examination & Ultrasonographical examination \\
\hline 1 & $\begin{array}{l}\text { Nausea, right upper quadrant } \\
\text { pain }\end{array}$ & $\begin{array}{l}\text { Right upper quadrant } \\
\text { tenderness }\end{array}$ & $\begin{array}{l}\text { Gallbladder wall thickening, } \\
\text { Multiseptate gallbladder, sludge, } \\
\text { multiple stones }\end{array}$ \\
$2-4$ & $\begin{array}{l}\text { Flank pain, asymptomatic for } \\
\text { biliary systems }\end{array}$ & Flank tenderness & $\begin{array}{l}\text { Multiseptate gallbladder } \\
\text { Phyrgian cap (in case 4) }\end{array}$ \\
5 & Recurrent aominal pain & Normal & Multiseptate gallbladder \\
$6-7$ & Recurrent epigastric pain & Normal & Multiseptate gallbladder \\
\hline
\end{tabular}


A

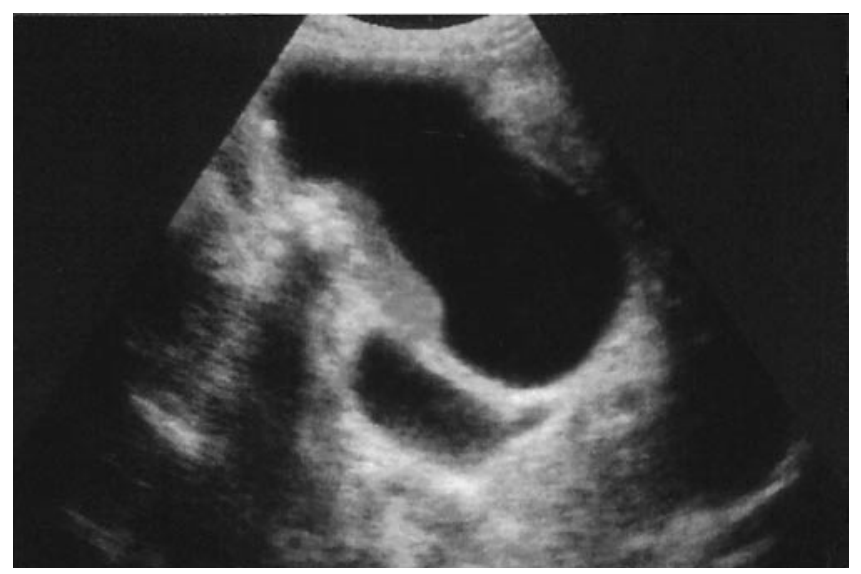

B

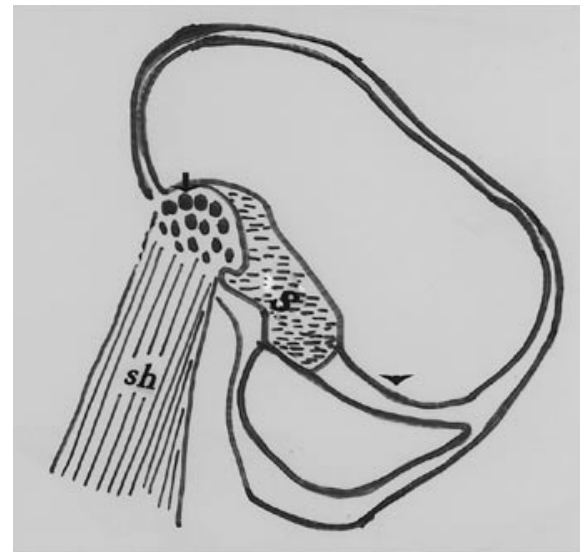

Fig. 1. Ultrasonography shows the septa which divide the gallbladder into multiple compartments, gallbladder sludge and multiple gallbladder stones with posterior acoustic shadowing (A). Schematic diagram of figure A, sh, acoustic shadow; S, sludge; black arrow, multiple stones; black arrow head, septa (B).

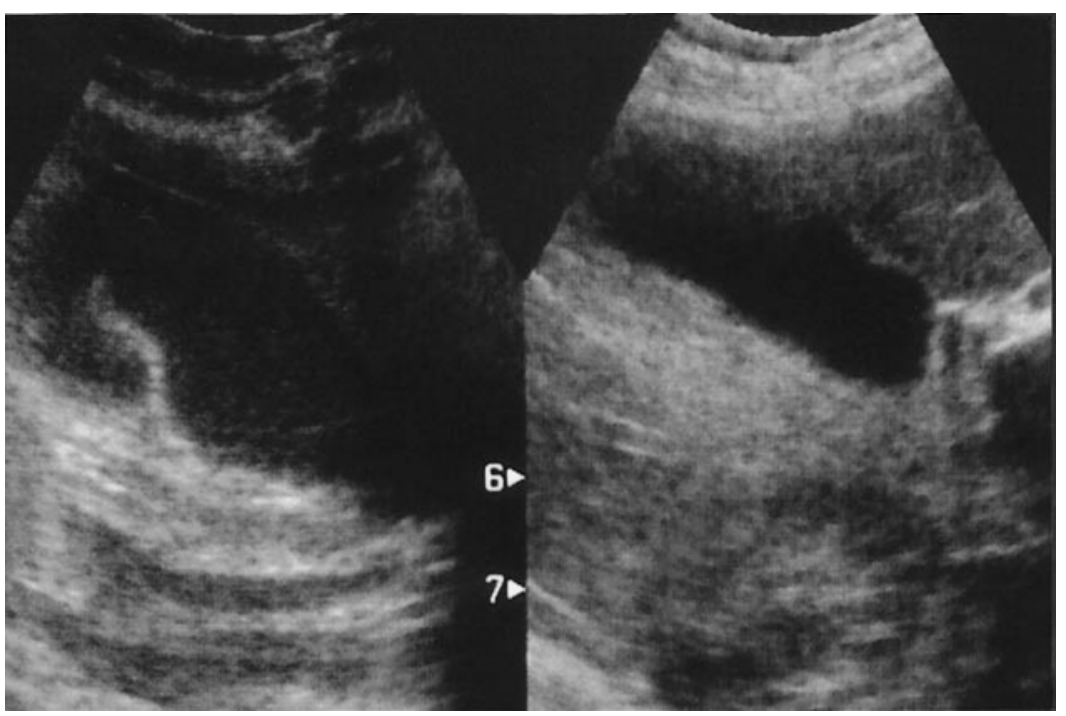

Fig. 2. Ultrasonography shows the folding of fundus of gallbladder over its corpus (Phrygian cap deformity) and the partial multiseptate gallbladder with neck involvement. Numbers 6 and 7 show the depth of the tissue in ultrasongraphic examination. 


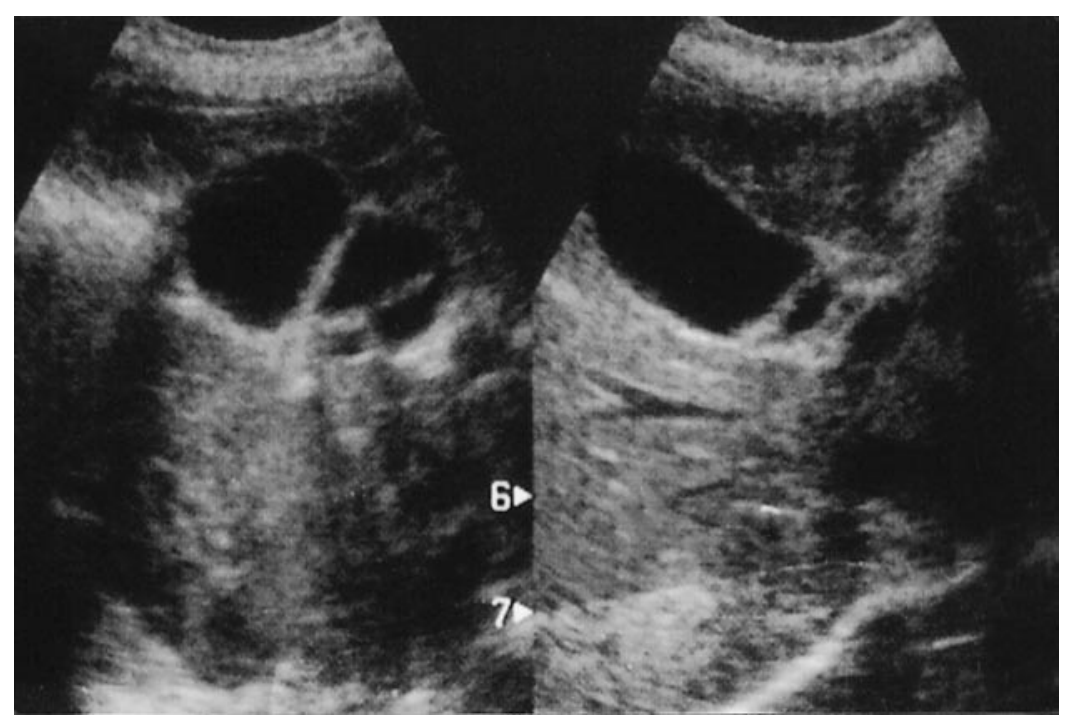

Fig. 3. Ultrasonography shows the multiple septa resembling honeycomb appearance located in the neck and corpus of the gallbladder. Numbers 6 and 7 show the depth of the tissue in ultrasonographic examination.

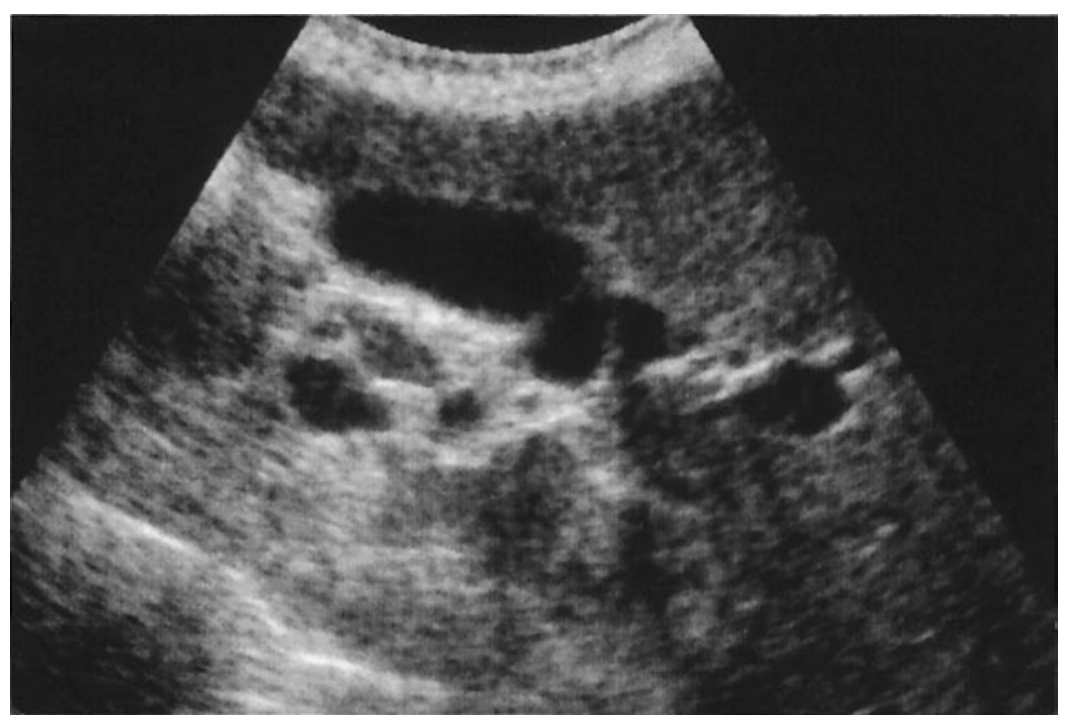

Fig. 4. Ultrasonography shows multiple septa and compartments in the neck of the gallbladder.

et al. 1992). Our case who has additional Phrygian cap deformity was asymptomatic and there were a few septa localized only to the neck of the gallbladder. Cholelithiasis with MSG similarly can cause right upper quadrant pain and recurrent abdominal pain as with other conventional cholelithiasis cases (Esper et al. 1992; Ozgen at al. 1992). Asymptomatic patients with MSG are very rare in the literature (Ozgen at al. 1992). In our study, three patients were asymptomatic and were diagnosed incidentally during control ultrasonograpy examination for nephrolithiasis.

Recurrent abdominal pain in childhood due to gallbladder disease is often misinterpreted as intestinal and genitourinary pathologies. Although gallbaldder disease in childhood is rare, the number of patients diagnosed per year seems to be increasing. Cholelithiasis and cholecystitis 
are very rare before puberty. If it is present, it is mostly related to bacterial and parasitic infections, hemolytic conditions and chronic gastrointestinal diseases (Esper et al. 1992). We think that the cause of the recurrent abdominal pain and calculous cholecytitis in the pediatric patient with MSG in our study was the mechanical effect of septa impairing normal bile flow. As these septa do not possess muscle fibers, a difficulty in bile flow is a consequence of the impaired motility of the gallbladder.

In the differential diagnosis of MSG, desquamated gallbladder mucosa and congenital or acquired intramural diverticulosis are also to be considered. Desquamated gallbladder mucosa is a rare finding of acute cholecystitis and is seen as multiple linear, non-shadowing densities within the gallbladder lumen. In diverticulosis, there is a cyst-like appearance within the gallbladder wall, with no bridging of the lumen (Lev-Toaff et al. 1987; Adear and Barki 1990).

In conclusion, MSG should be considered among the diagnosis of recurrent abdominal pain, especially in the pediatric age group. MSG should also be thought among the etiologic factors of cholelithiasis and cholecystitis.
Ultrasonographic follow-up is enough for asymptomatic MSG cases.

\section{References}

Adear, H. \& Barki, Y. (1990) Multiseptate gallbladder in a child: incidental diagnosis on sonography. Pediatric Radiolgy., 20, 192.

Esper, E., Kaufman, D.B., Crary, G.S., Snover, D.C. \& Leonard, A.S. (1992) Septate gallbladder with cholelithiasis: a cause of chronic abdominal pain in a 6-year-old child. J. Pediatr. Surg., 27, 1560-1562.

Laing, F.C. (1987) Ultrasonography of the gallbladder and biliary tree. In: Diagnostic Ultrasound: Text and Cases. edited by Sarti, D.A. 2nd ed., St. Louis, Mosby-Year Book., pp. 107-108.

Lev-Toaff, A.S., Friedman, A.C., Rindsberg, S.N., Caroline, D.F., Maurer, A.H. \& Radecki, P.D. (1987) Multiseptate gallbladder: incidental diagnosis on sonography. AJR Am. J. Roentgol., 148, 1119-1120.

Miwa, W., Toyama, W., Kitamura, Y., Murakami, K., Kamata, K., Takada, T., Tanabe, H. \& Kanayama, M. (2000) Multiseptate gallbladder with cholelithiasis diagnosed incidentially in an elderly patient. Intern. Med., 39, 1054-1059.

Ozgen, A., Akata, D., Ozmen, M.N. \& Akhan, O. (1999) Case report: Multiseptate gallbladder. Turk. J. Diagn. Intervent. Radiol., 5, 496-498. 